\title{
Application of Pulsed Laser Fabrication in Localized Corrosion Research
}

\author{
M. Sakairi'1, K. Yanada ${ }^{2}$, T. Kikuchi ${ }^{1}$, Y. Oya ${ }^{3}$ and Y. Kojima ${ }^{3}$ \\ ${ }^{1}$ Faculty of Engineering, Hokkaido University, Kita-13, \\ Nishi-8, Kita-ku, Sapporo \\ ${ }^{2}$ Graduate School of Engineering, Hokkaido University, Kita-13, \\ Nishi-8, Kita-ku, Sapporo \\ ${ }^{3}$ Technical Research Division, Furukawa-Sky Aluminum Corp., \\ Akihabara UDX, Sotokanda 4-chome, Chiyoda-ku, Tokyo \\ Japan
}

\section{Introduction}

Aluminum and its alloys have been known as light metals because they are used to reduce the weight of automobiles and components. Aluminum is the second most used and produced metal in the world nowadays. It is well known that one of the typical corrosion morphologyies of aluminum alloys in chloride containing environments such as seawater is pitting corrosion. Many papers have been investigating pitting corrosion ((Ito et al., 1968), (Horibe et al., 1969), (Goto et al. 1970), (Blanc et al., 1997), (Kang et al., 2010)). Electrochemical techniques, such as model macro-pits (Itoi et al., 2003) and electrochemical noise analysis (Sakairi et al., 2005, 2006, 2007) have been applied to investigate pitting corrosion of aluminum alloys.

Details of the propagation of pitting corrosion (Fig. 1) are not fully understood, however, the aspect ratio of pits (pit depth/pit diameter) plays a very important role in the growth of corrosion pits (Toma et al., 1980). To understand this effect, an in-situ artificial pit fabrication technique with area selective dissolution measurements would be helpful. One such technique is pulsed laser fabrication, which uses focused pulsed Nd-YAG laser beam irradiation to remove material from the substrate, combined with anodizing. Some of the authors have reported on the electrochemical behavior of artificial pits fabricated on aluminum alloy ((Sakari et al., 2009), (Yanada et al., 2010)).

In this chapter, the results of the effect of aspect ratio on dissolution behavior of the artificial pits formed on aluminum alloys are explained, and the chapter also explains the rate of pit fabrication and how to activate only the bottom surface of the formed pits.

\section{Artificial pit fabrication by pulsed laser}

\subsection{Experimental}

Sheet specimens of $2024(15 \times 20 \times 2.0 \mathrm{~mm})$ and $1050(15 \times 20 \times 1.1 \mathrm{~mm})$ aluminum alloys were used. Table 1 shows the chemical composition of the used aluminum alloys. Specimens were cleaned in doubly distilled water and an ethanol ultrasonic bath, and then polished 


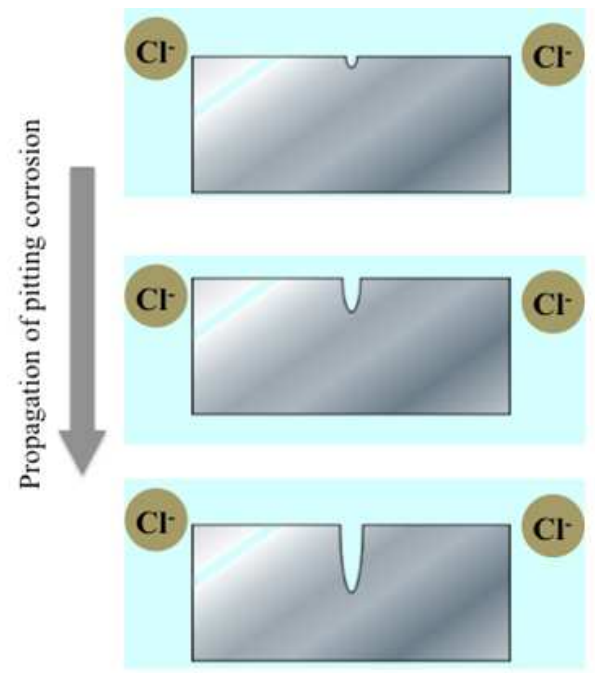

Fig. 1. Schematic representation of propagation of pitting corrosion in chloride ion containing solutions.

\begin{tabular}{ccccccccc}
\hline & Si & Fe & Cu & Mn & Mg & Zn & other & Al \\
\hline 2024 & 0.06 & 0.20 & 4.78 & 0.59 & 1.43 & 0.07 & 0.26 & balance \\
\hline 1050 & 0.08 & 0.27 & 0.03 & - & - & - & 0.05 & balance \\
\hline
\end{tabular}

Table 1. Chemical compositions of used aluminum alloys.

chemically in $0.1 \mathrm{kmol} \mathrm{m}^{-3} \mathrm{NaOH}$ for $1800 \mathrm{~s}$. A protective film is required to investigate the electrochemical reactions at only the laser beam irradiated area, and porous type anodic oxide films were formed at a constant current density of $100 \mathrm{~A} \mathrm{~m}^{-2}$ in $0.22 \mathrm{kmol} \mathrm{m}^{-3}$ $\mathrm{C}_{2} \mathrm{H}_{2} \mathrm{O}_{4}$ at $293 \mathrm{~K}$ for $1800 \mathrm{~s}$. Anodized specimens were dipped in boiling doubly distilled water for $900 \mathrm{~s}$ (pore sealing) to improve the protective performance of the formed anodic oxide films.

Specimens with protective films were irradiated by a focused Nd-YAG laser beam (Sepctra Physics GCR-130, wave duration $8 \mathrm{~ns}$, frequency $10 \mathrm{~s}^{-1}$, wave length $532 \mathrm{~nm}$ ) for $\mathrm{t}_{\mathrm{i}}=0$ to $30 \mathrm{~s}$ while immersed in $0.5 \mathrm{kmol} \mathrm{m}^{-3} \mathrm{H}_{3} \mathrm{BO}_{3}-0.05 \mathrm{kmol} \mathrm{m}^{-3} \mathrm{Na}_{2} \mathrm{~B}_{4} \mathrm{O}_{7}$ (Borate). The laser beam power was adjusted to $30 \mathrm{~mW}$ in front of the lens. Fig. 2 shows a schematic outline of the laser irradiation and electrochemical measurement apparatus used in this chapter.

Surface and pit size observations: Specimen surfaces after the experiments were examined by an optical microscope, confocal scanning laser microscope (CSLM; 1SA21, LASERTEC Co.), and a scanning electron microscope (SEM; TM 1000, Hitachi Co.). The formed artificial pit depths and geometry were measured with the analysis function of the CSLM and X-ray Computed Tomography (X-ray CT; ELE SCAN mini, NS-ELEX Co. Ltd.). 


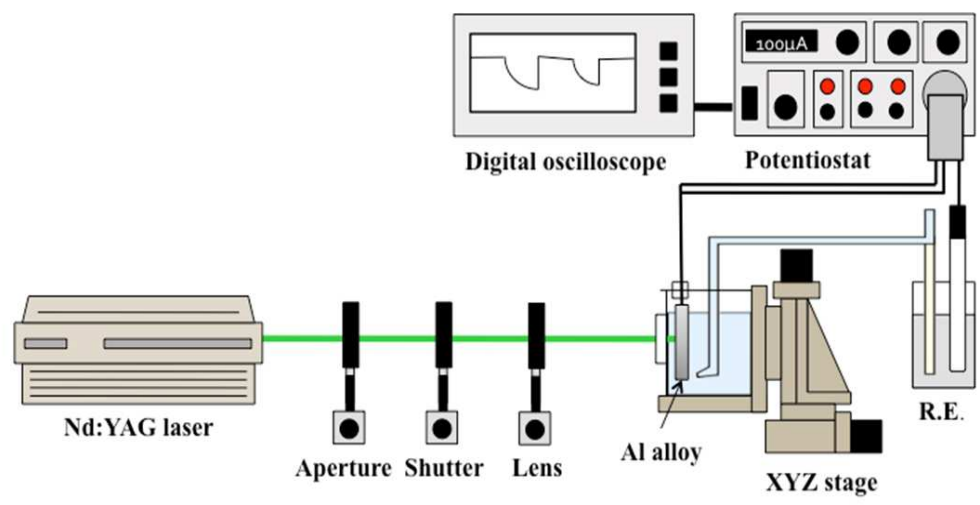

Fig. 2. Schematic representation of the laser irradiation and electrochemical measurement apparatus.

\subsection{Results and discussion}

\subsubsection{Kinetics of pit fabrication}

Artificial pit depth and morphology changes with continuous laser beam irradiation time were investigated in Borate. Fig. 3 shows SEM surface images of laser beam irradiated 2024 aluminum alloy specimens at $t_{i}=0.1$ to $150 \mathrm{~s}$. The anodic oxide film and aluminum alloy substrate can be removed at the irradiated area, and the shape of the area where oxide film was removed is almost circular. The center of the oxide film removed area is bright initially and then becomes dark with $t_{i}$, and it becomes larger with $t_{i}$.
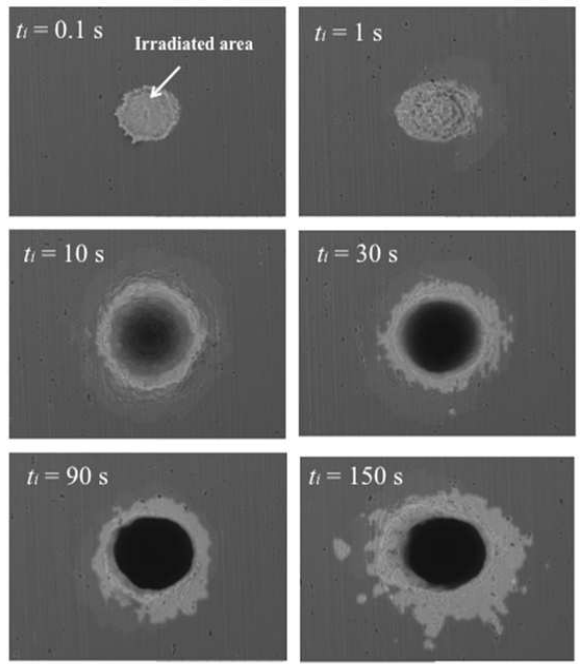

$300 \mu \mathrm{m}$

Fig. 3. SEM surface images of fabricated artificial pits on 2024 aluminum ally at different laser beam irradiation times. 
Figure 4 shows X-ray CT vertical sectioning images of fabricated artificial pits on 2024 aluminum alloy. Fig. 5 shows horizontal section images of $a t_{i}=150 \mathrm{~s}$ pit and a schematic representation of the section positions. From Fig. 4, the depth of a fabricated pit becomes deeper with longer $t_{\mathrm{i}}$. From the horizontal sectional images in Fig. 5, the shape of fabricated artificial pits are almost completely circular from the top to the bottom.
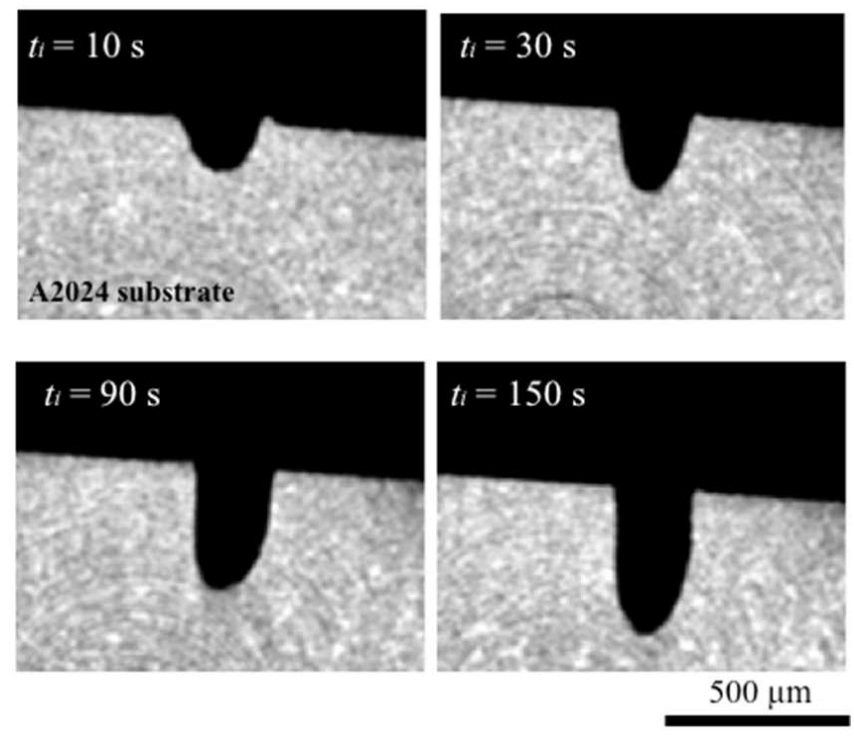

Fig. 4. X-ray computed tomography (X-ray CT) vertical section images of fabricated artificial pits on 2024 aluminum alloy.
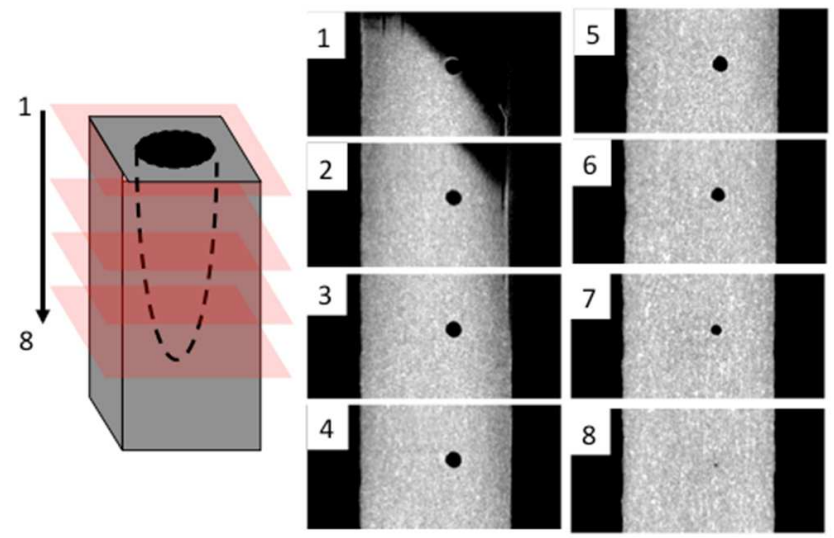

$1 \mathrm{~mm}$

Fig. 5. X-ray CT horizontal section images of pits fabricated on 2024 aluminum alloy $\left(t_{\mathrm{i}}=150 \mathrm{~s}\right)$ and schematic representation of section positions. 


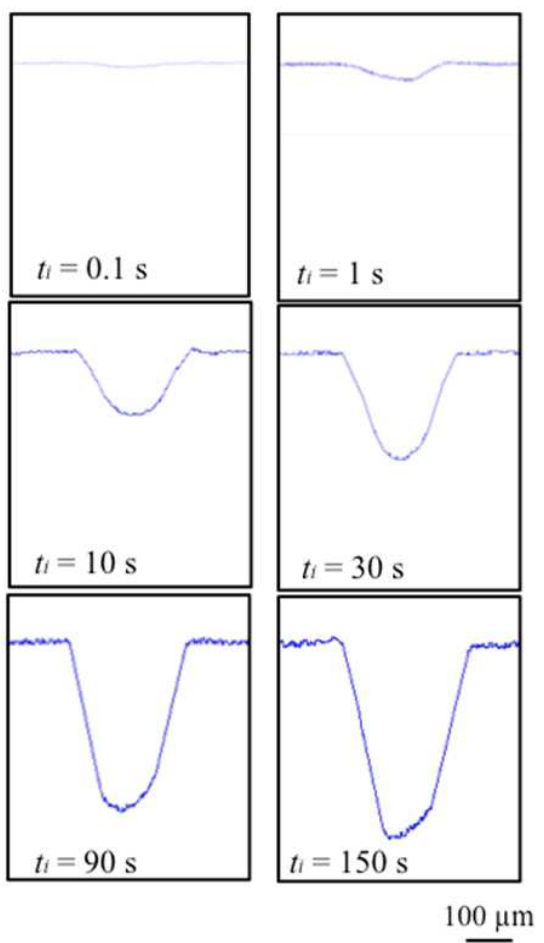

Fig. 6. CLSM depth profiles of fabricated artificial pits in 2024 aluminum alloy.

Figure 6 shows CSLM depth profile of fabricated pits with $t_{\mathrm{i}}$. The CSLM depth profile also shows that the center area of the laser beam irradiated area is deeper than the other areas. The pit becomes deeper with $t_{i}$, however, the cross-sectional shape is independent of $t_{i}$. Figure 7 shows changes in diameter (width) of artificial pits fabricated in both the 1050 and 2024 aluminum alloys with $t_{i}$. The pit diameter increases sharply at $t_{i}<1 \mathrm{~s}$ and the slope of the diameter change curve becomes flatter with longer $t_{i}$. The value of the diameter of 1050 aluminum alloy is about $20 \%$ lager than that of 2024 aluminum alloy. The laser beam used here has a Gaussian energy distribution and aluminum metal changes to gas or plasma only at the center of the irradiated area. However, the outer rim of the laser beam has sufficient energy to melt the aluminum substrate. This melted metal was ejected or flows by the effect of the evaporated gas or formed plasma (Fig. 8). If the irradiating conditions do not change during the experiments, then, after some time, the size of the melted area would not change with $t_{i}$.

Figure 9 shows the increases in depth of artificial pits fabricated on both the 1050 and 2024 aluminum alloys with $t_{i}$. The pit depth increases sharply at $t_{i}<1 \mathrm{~s}$ and the slope of the depth change curve becomes flatter with $t_{i}$. The specimen did not move during the laser beam irradiation, and therefore the distance between lens and irradiated surface (bottom of the pit) becomes longer with $t_{i}$. This distance change causes a decrease in the mean beam energy available for pit fabrication. This is a reason why the slope of the pit depth change curve becomes flatter with $t_{i}$. The pit formation rate of the 1050 aluminum alloy is about twice that of the 2024 aluminum alloy. 


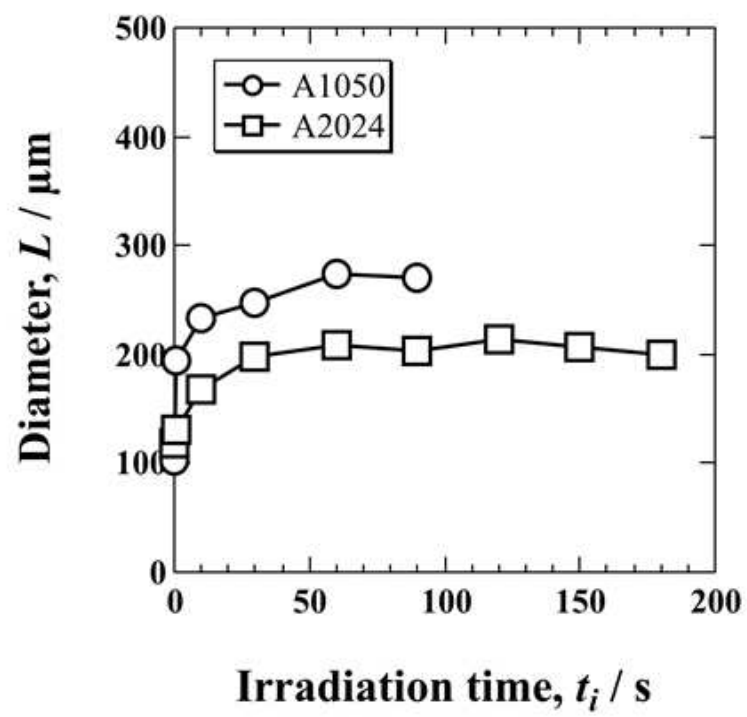

Fig. 7. Changes in the diameters of fabricated artificial pits on 1050 and 2024 aluminum alloys as a function of. irradiation time.

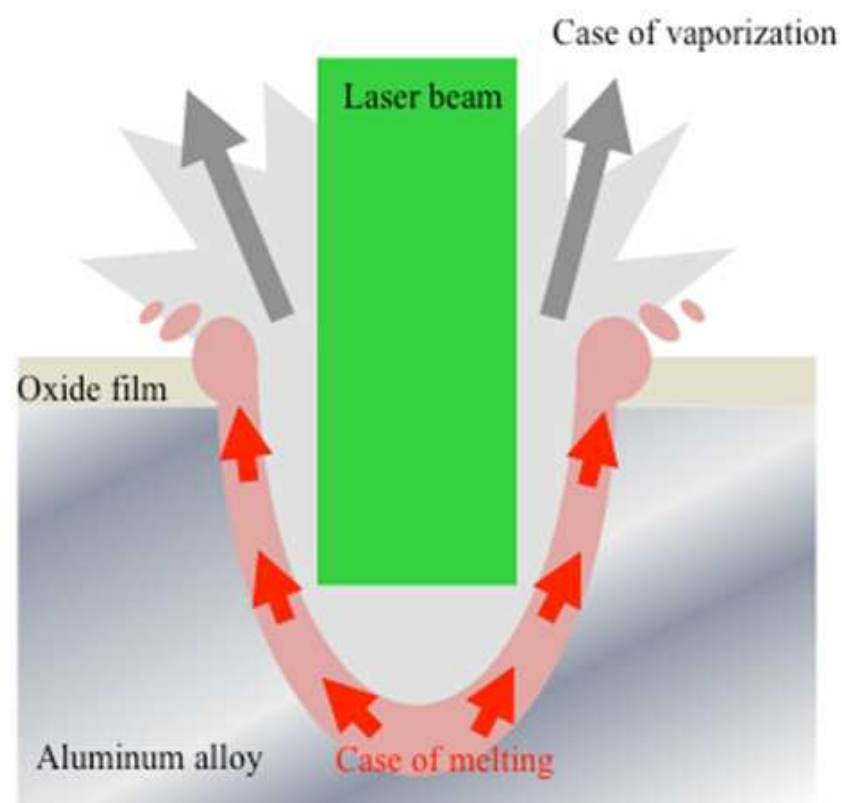

Fig. 8. Schematic representation of pit fabrication mechanism by continuous laser beam irradiation. 


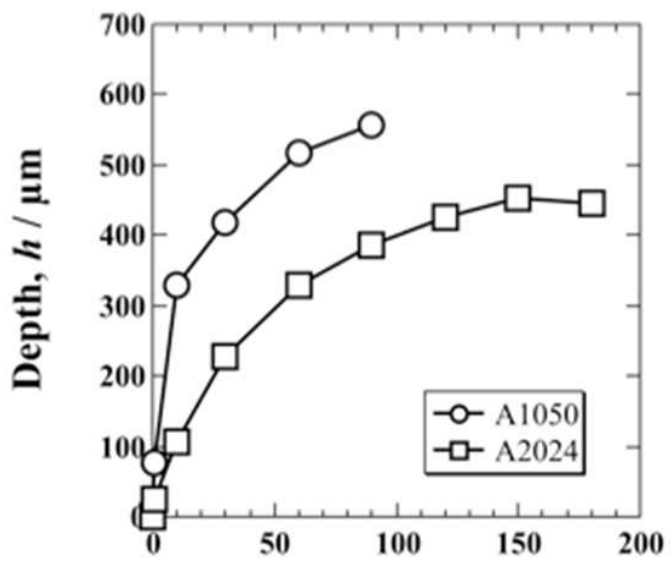

\section{Irradiation time, $t_{i} / \mathrm{s}$}

Fig. 9. Changes in the depths of fabricated artificial pits as a function of irradiation time.

These results shown here clearly substantiate that continuous focused pulse laser beam irradiation makes it possible to fabricate artificial pits on aluminum alloy in solutions, and the shape of the pits appear to be bell shaped. The detailed mechanism of pit fabrication is explained in section 2.2.2, but a possible mechanism is laser ablation.

Figure 10 shows changes in aspect ratio with $t_{i}$ for both the 1050 and 2024 aluminum alloys. The aspect ratio of the formed pits on both aluminum alloys increases with $t_{i}$ and the aspect ratio of both aluminum alloys at the same $t_{i}$ are similar. This result shows that the proposed technique here makes it possible to fabricate artificial pits with different aspect ratios (0.13 2.3) on anodized aluminum in solutions.

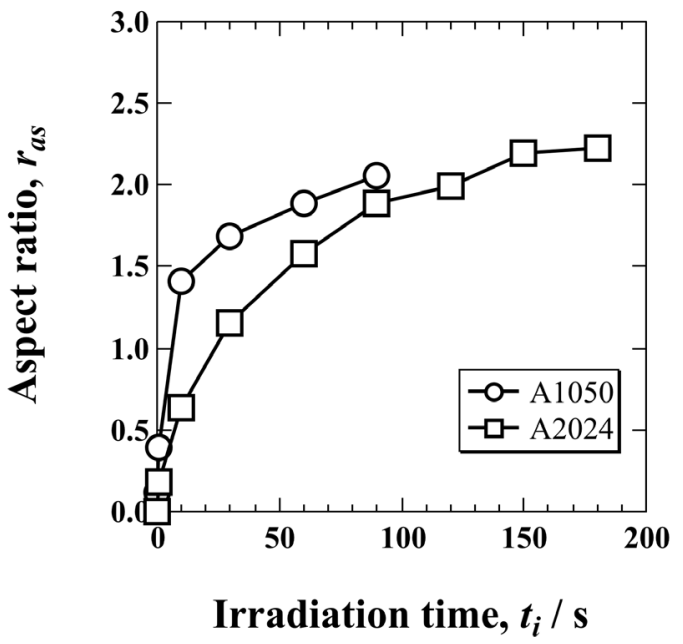

Fig. 10. Changes in the aspect ratios of fabricated artificial pits as a function of irradiation time. 


\subsubsection{Pit fabrication mechanism}

The detailed explanation of laser ablation to remove oxide film or metals is shown in the literature (Sakairi et al., 2007).

Anodic oxide films formed on aluminum alloys are almost completely transparent at the laser frequency of 532nm used here. As continuous irradiation, oxide films are removed after several irradiation pulses by the laser beam. These situations indicate that almost all of the irradiated laser light energy reaches the metal-oxide interface or metal surface. It is not certain that the reflectivity of high energy density light is the same as low energy density beams, however, the reported reflectivity value of 0.82 at $532 \mathrm{~nm}$ (Waver, 1991-1992) is used to estimate the adsorbed power density here. The adsorbed power density in this experimental condition, with the wave duration $8 \mathrm{~ns}$, frequency $10 \mathrm{~s}^{-1}$, irradiated diameter $300 \mu \mathrm{m}$, and $\mathrm{P}=3.0 \mathrm{~mJ}(30 \mathrm{~mW} / 10 \mathrm{~Hz})$ becomes about $10^{12} \mathrm{~W} / \mathrm{m}^{2}$. According to the literature (Ready, 1971), the approximate expression of the minimum laser power density for ablation of aluminum $\left(\mathrm{r}=2700 \mathrm{~kg} \mathrm{~m}^{-3}, \mathrm{~L}=10778 \mathrm{~kJ} \mathrm{~kg}^{-1}, \mathrm{k}=1.0 \times 10^{-4} \mathrm{~m}^{2} \mathrm{~s}^{-1}\right)$ is about 0.7 $\mathrm{x} 1012 \mathrm{~W} / \mathrm{m}^{2}$. The value of the adsorbed power density in the present investigation is larger than that of ablation of aluminum. This suggests that laser ablation takes place beneath the area where the laser was irradiated. The ablation of metal produces pressure at the film/substrate or solution/substrate interfaces immediately after the irradiation. The pressure of laser ablation is simply calculated by using the laser power density for ablation, the specific thermal capacity of the aluminum, the initial, and the vaporization temperatures of the aluminum (Scruby, 1990). The estimated value is about $10^{8} \mathrm{~Pa}$. The deformation pressures of micro-filters made of porous type anodic oxide films with $45 \mu \mathrm{m}$ thickness is about $2 \times 10^{8} \mathrm{~Pa}$, and the pressures are proportional to the film thickness (Hoshino et al., 1997). The pressure estimated here is almost same as the deformation pressure of the thick porous type anodic oxide film. It may be concluded that the anodic oxide film and aluminum substrate can be destroyed and removed by the high pressure at the interface produced by the laser ablation of the aluminum substrate itself.

\section{Corrosion behavior in formed artificial pits}

\subsection{Experimental}

Borate with 0 to $0.01 \mathrm{kmol} \mathrm{m}^{-3} \mathrm{NaCl}$ was used as electrolyte for the corrosion tests. An $\mathrm{Ag} / \mathrm{AgCl}$ sat. $\mathrm{KCl}$ electrode was used as the reference electrode, and Pt plate $(2 \times 2 \mathrm{~cm})$ was used as the counter electrode.

Polarization curves of chemically polished 2024 alloy specimens (un-anodized) were measured to determine the optimum applied potential and $\mathrm{Cl}^{-}$concentration for investigation of the effect of the aspect ratio on the current transient in the artificial pits. In this experiment, the potential was swept at the constant rate of $0.83 \mathrm{mV} / \mathrm{s}$ from the rest potential to the anodic potential direction.

Two different types of electrochemical corrosion tests were carried out after fabrication of artificial pits with different aspect ratios on 2024 alloy, namely with the current transients at constant potential and with the rest potential changing.

Current transients: Artificial pits with two different depths formed by $t_{i}=1 \mathrm{~s}$ and $120 \mathrm{~s}$ were formed in Borate with $0.01 \mathrm{kmol} \mathrm{m}^{-3} \mathrm{NaCl}$, then a constant potential of $-300 \mathrm{mV}$ was applied. The current was measured to establish that no further dissolution or passivation was occurring in the pits, and after that one more pulse of laser light was applied to activate the bottom of the pits. The current transients after the activation were measured with a digital oscilloscope (Yokogawa Electric Co., DL708E). 
Rest potential: The artificial pits with two different depths formed at $t_{i}=1 \mathrm{~s}$ to $120 \mathrm{~s}$ were formed in Borate with 0.001 to $0.01 \mathrm{kmol} \mathrm{m}^{-3} \mathrm{NaCl}$, then the bottom of the pits were activated by one more pulse of laser light. After the activation, the rest potential was measured with the digital oscilloscope.

One of the authors have reported on the effect of an aperture on the oxide film removed area (Sakairi et al., 1998). Using an aperture makes it possible to narrow the irradiated area at the focus point. Therefore, to activate only the bottom of the pits, an aperture placed in front of the lens was used. In the case of specimens with deep pits, $t_{i}=10 \mathrm{~s}$ to $120 \mathrm{~s}$, the distance between lens and pit bottom was adjusted to focus the point of the used lens by using an XYZ stage (Fig. 1).

After the experiments, the specimen surfaces were examined by an optical microscope.

\subsection{Results and discussion}

\subsubsection{Polarization results}

The potentio-dynamic polarization curves of chemically polished 2024 aluminum alloys were measured in Borate with different concentrations of $\mathrm{NaCl}$ (Fig. 11) to determine the $\mathrm{Cl}^{-}$ concentration and applied potential for electrochemical corrosion tests of the artificial pits. The rest potential shifts to lower potentials with higher $\mathrm{NaCl}$ concentrations. At the low $\mathrm{Cl}^{-}$ concentration of $0.001 \mathrm{kmol} \mathrm{m}^{-3}$, the relationship between current density and potential shows no changes due to the added $\mathrm{Cl}^{-}$. No current fluctuations are observed reveals suggesting that no localized corrosion is taking place. However, at higher $\mathrm{Cl}^{-}$concentrations $\left(>0.002 \mathrm{kmol} \mathrm{m}^{-2}\right)$, the current shows sudden increases at the start of the polarization with further current fluctuations. This result at the higher $\mathrm{Cl}^{-}$concentrations shows that when

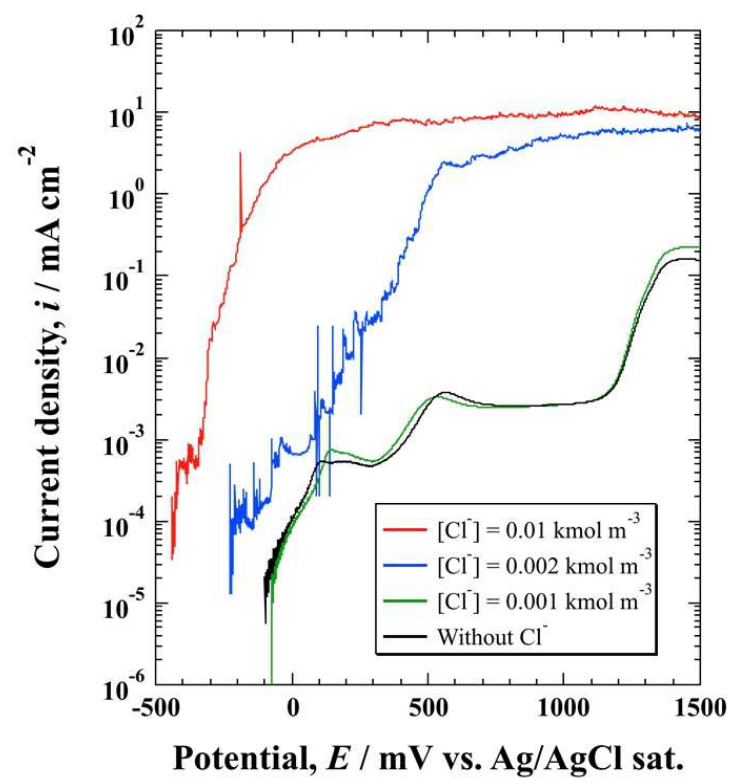

Fig. 11. Potentio-dynamic anodic polarization curves of chemically polished 2024 aluminum alloy in $0.5 \mathrm{kmol} \mathrm{m}^{-3} \mathrm{H}_{3} \mathrm{BO}_{3}-0.05 \mathrm{kmol} \mathrm{m}^{-3} \mathrm{Na}_{2} \mathrm{~B}_{4} \mathrm{O}_{7}$ with 0 to $0.01 \mathrm{kmol} \mathrm{m}^{-3} \mathrm{NaCl}$. 
aluminum substrate becomes exposed to the solution by laser beam irradiation, pitting corrosion tends to occur even at the open circuit condition. From these results, Borate with $0.01 \mathrm{kmol} \mathrm{m}^{-3} \mathrm{NaCl}$ and an applied potential of $-0.3 \mathrm{~V}$ was chosen for the electrochemical measurements of the artificial pits formed on the 2025 aluminum alloy. To investigate the effect of $\mathrm{Cl}^{-}$concentration on pit propagation at open circuit condition (no potential applied), Borate with 0.001 and $0.01 \mathrm{kmol} \mathrm{m}^{-3} \mathrm{NaCl}$ were chosen.

\subsubsection{Current measurements}

Figure 12 shows changes in the current of the pits formed on 2024 aluminum alloy with $t_{i}=$ $1 \mathrm{~s}$ and $120 \mathrm{~s}$ after activation by 1 pulse of laser beam irradiation at $-0.3 \mathrm{~V}$ in Borate with 0.01 $\mathrm{kmol} \mathrm{m}^{-3} \mathrm{NaCl}$. After the laser beam irradiation, the current increased instantaneously through a maximum, then decreases with time in both pit conditions. After the test, white corrosion products can be seen on the specimen surfaces at the pit (Fig. 13).

Figure 14 shows changes in rest potential during and after pit formation on 2024 aluminum alloy in Borate with $0.01 \mathrm{kmol} \mathrm{m}^{-3} \mathrm{NaCl}$. Results with specimens without pits are also shown in the figure to evaluate the protectiveness of the anodic oxide film. The rest potential in both irradiated specimens show negative values during pit fabrication, and then there are increases after the pit fabrication. Fluctuations which relate to localized corrosion events are also observed in the rest potential changes. There are no very large potential fluctuations in the results for the anodized specimens here, indicating that anodic oxide film has good corrosion resistance for long times and that the measured potential fluctuations are related to events inside the formed pits.

Figure 15 shows changes in the rest potential during and after pit formation on 2024 aluminum alloy in Borate with $0.001 \mathrm{kmol} \mathrm{m}^{-3} \mathrm{NaCl}$. The changes in the rest potential at each $t_{i}$ are very similar to those in Fig. 14, with no significant fluctuations observed. This means that the formed pits are repassivated after some time of pit formation, because of the low $\mathrm{Cl}^{-}$ concentration.

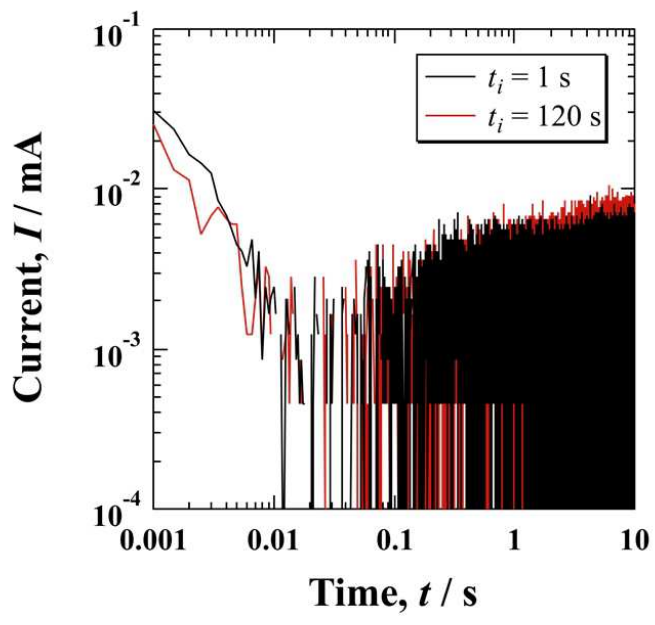

Fig. 12. Changes in the current of the pit formed on 2024 aluminum alloy after activation by one pulse of laser beam irradiation at $-0.3 \mathrm{~V}$ in $0.5 \mathrm{kmol} \mathrm{m}^{-3} \mathrm{H}_{3} \mathrm{BO}_{3}-0.05 \mathrm{kmol} \mathrm{m}^{-3} \mathrm{Na}_{2} \mathrm{~B}_{4} \mathrm{O}_{7}$ with $0.01 \mathrm{kmol} \mathrm{m}^{-3} \mathrm{NaCl}$. 


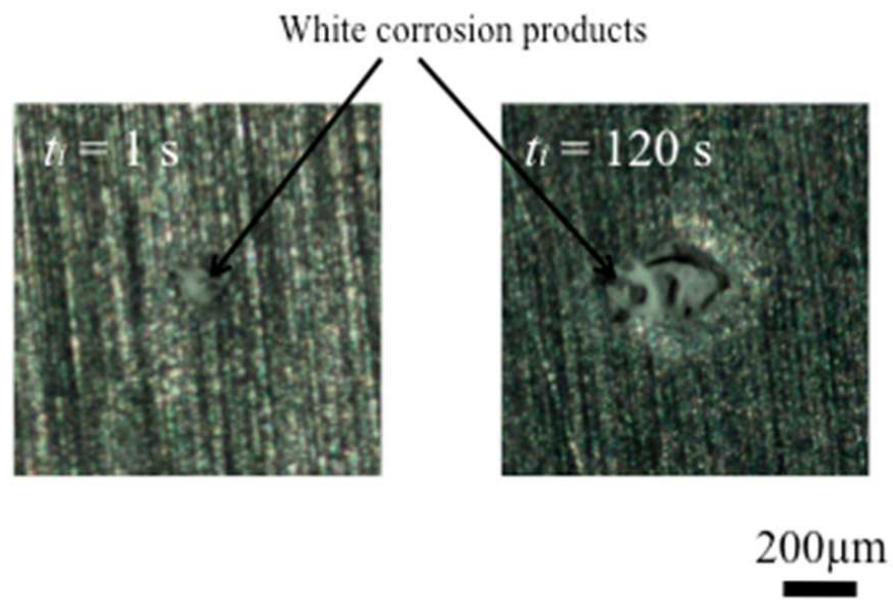

Fig. 13. Optical images of specimen surfaces after the test in Fig. 12.

Figure 16 shows rest potentials $2400 \mathrm{~s}$ after the finish of the pit fabrication, $\mathrm{E}_{2400}$, in Fig. 15 as a function of $t_{i}$. The $E_{2400}$ decreases with increasing $t_{i}$, suggesting pit depth or aspect ratio influence on the protective thin oxide film formation or differences in repassivation kinetics. Figure 17 shows different stages of rest potential changes by polarization curves at each step of the pit formation process. During the pit formation, the aluminum substrate is frequently activated causing increases in anodic currents and decreases in the rest potential. After the pit formation, the aluminum substrate is not further activated by the laser irradiation, and there is repassivation or further localized corrosion progresses in higher concentrations $\mathrm{Cl}^{-}$solutions. If the surface repassivates, the anodic current decreases causing rest potential increases.

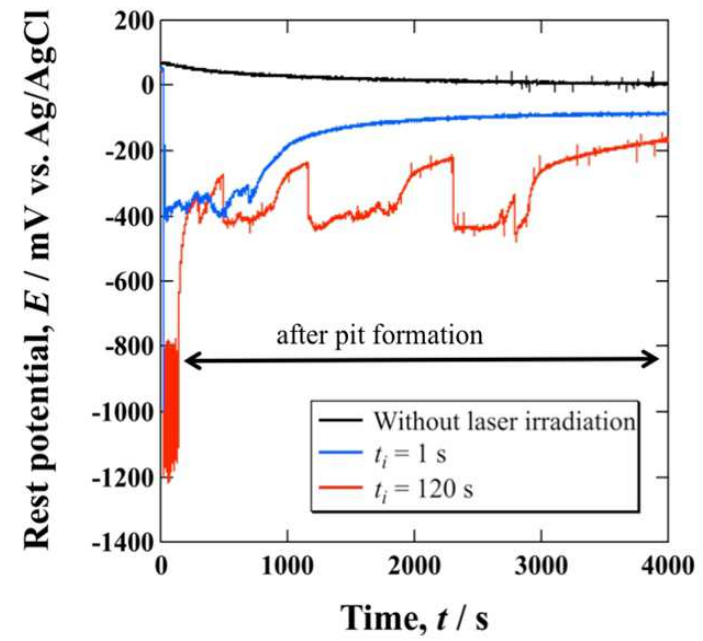

Fig. 14. Changes in rest potential during and after pit formation in $0.5 \mathrm{kmol} \mathrm{m}^{-3} \mathrm{H}_{3} \mathrm{BO}_{3}-0.05$ $\mathrm{kmol} \mathrm{m}^{-3} \mathrm{Na}_{2} \mathrm{~B}_{4} \mathrm{O}_{7}$ with $0.01 \mathrm{kmol} \mathrm{m}^{-3} \mathrm{NaCl}$. The rest potential of specimens without pits is also shown in the figure. 


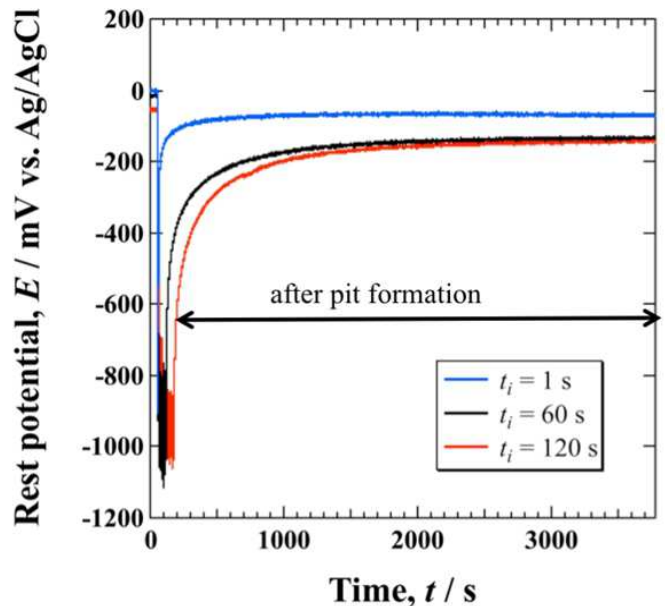

Fig. 15. Changes in rest potential during and after pit formation on 2024 aluminum alloy in $0.5 \mathrm{kmol} \mathrm{m}^{-3} \mathrm{H}_{3} \mathrm{BO}_{3}-0.05 \mathrm{kmol} \mathrm{m}^{-3} \mathrm{Na}_{2} \mathrm{~B}_{4} \mathrm{O}_{7}$ with $0.001 \mathrm{kmol} \mathrm{m}^{-3} \mathrm{NaCl}$

To investigate the effect of pit aspect ratio on the repassivation kinetics, the bottom of the pit was re-activated by one pulse of laser beam irradiation. The re-activation was carried out $2400 \mathrm{~s}$ after completion of the pit formation. Fig. 18 shows the changes in the rest potential after this re-activation of 2024 aluminum alloy in Borate with $0.001 \mathrm{kmol} \mathrm{m}^{-3} \mathrm{NaCl}$. The potential changes to the negative direction in all specimens, shows a minimum value, and then shifts to the positive direction. This potential shift to the positive direction suggests repassivation of the re-activated surface at the bottom of the pit.

Figure 19 shows optical images after the re-activation tests. No corrosion products are observed in either the $t_{i}=1 \mathrm{~s}$ or $120 \mathrm{~s}$ specimens. This result suggest that repassivation took place because of the low concentration of $\mathrm{Cl}^{-}$, in good agreement with the potential changes in Fig. 18.

The lowest rest potential after the re-activation as a function of aspect ratio is shown in Fig. 20. Low aspect ratio samples show the lowest reached potential, while higher aspect ratio specimens show very similar values.

To clarify the effect of the aspect ratio on the repassivation kinetics, a repassivation ratio concept is introduced. The repassivation ratio, $r_{p}$, is explained as follows

$$
\begin{aligned}
& r_{P}=\frac{\Delta E_{p}}{\Delta E_{a c}} \\
& \Delta E_{a c}=E_{2400}-E_{a c} \\
& \Delta E_{p}=E_{p}-E_{a c}
\end{aligned}
$$

where $E_{2400}$ is the rest potential $2400 \mathrm{~s}$ after pit formation, $E_{a c}$ is the lowest rest potential after re-activation, and $E_{p}$ is the average value of the rest potential around $0.01 \mathrm{~s}$ or $10 \mathrm{~s}$ after the re-activation. Therefore, a high value of $r_{p}$ indicates that repassivation has progressed.

Changes in $r_{p}$ at $t_{c}=0.01 \mathrm{~s}$ (Fig. 21) and $10 \mathrm{~s}$ (Fig. 22) with the aspect ratio of the pit in Borate with $0.001 \mathrm{kmol} \mathrm{m}^{-3} \mathrm{NaCl}$ were established. The $r_{p}$ of the 1050 aluminum alloy is also shown 


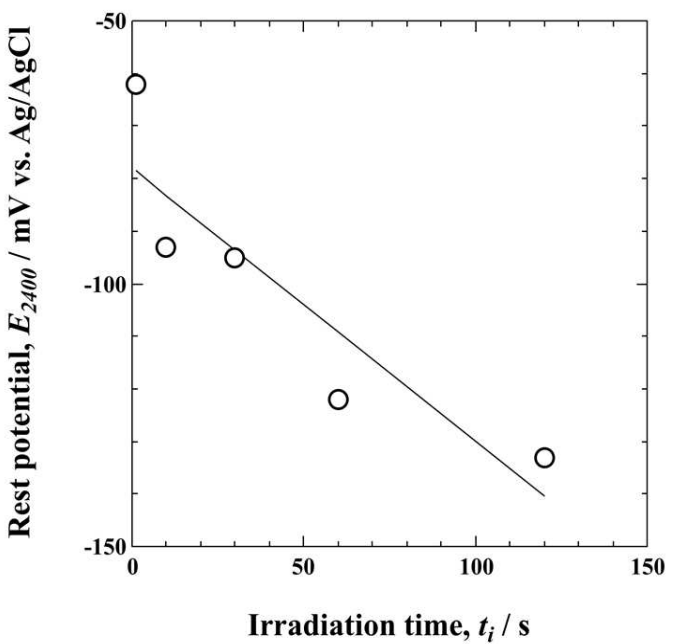

Fig. 16. Rest potential at $2400 \mathrm{~s}$ after the finish of the pit fabrication in Fig. 15 as a function of the aspect ratio of the formed pits.
(a) Before pit formation
(b) During pit formation
(c) After pit formation
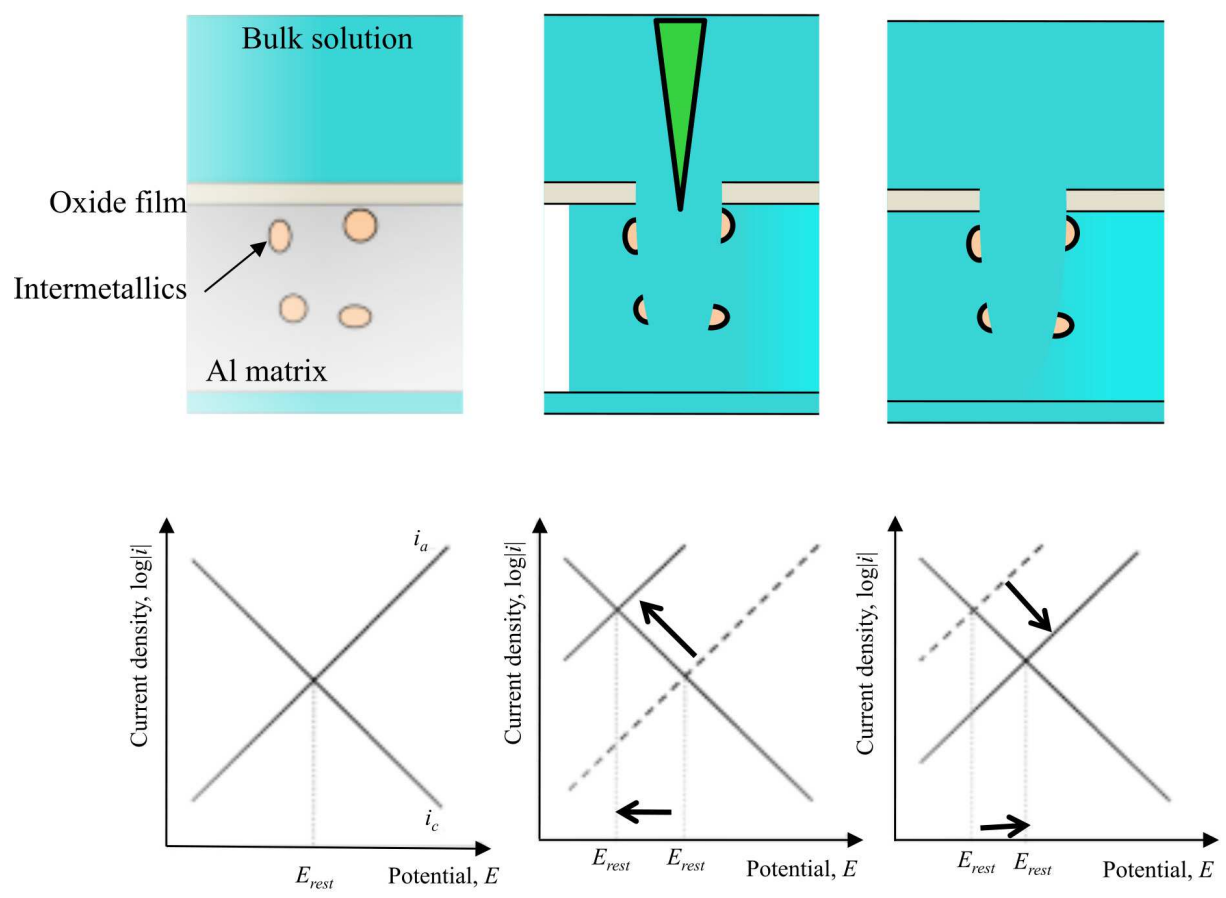

Fig. 17. Schematic representation of rest potential changes by polarization curves at each step of the pit formation process. 


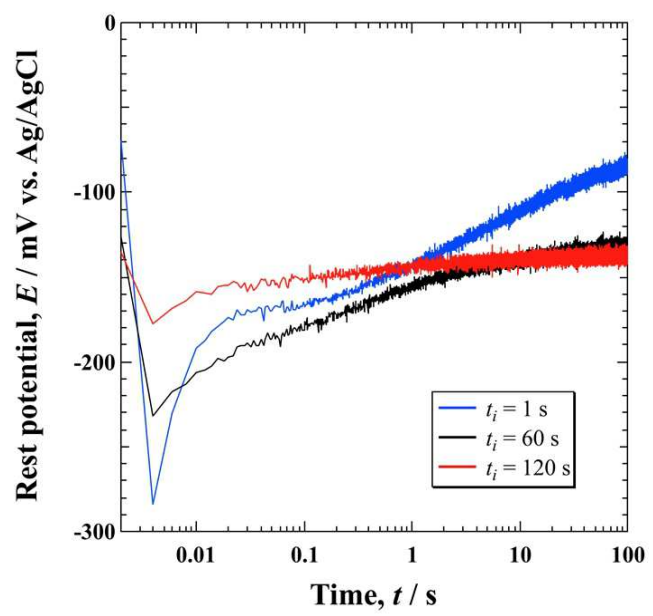

Fig. 18. Changes in rest potential after the re-activation of 2024 aluminum alloy in $0.5 \mathrm{kmol}$ $\mathrm{m}^{-3} \mathrm{H}_{3} \mathrm{BO}_{3}-0.05 \mathrm{kmol} \mathrm{m}^{-3} \mathrm{Na}_{2} \mathrm{~B}_{4} \mathrm{O}_{7}$ with $0.001 \mathrm{kmol} \mathrm{m}^{-3} \mathrm{NaCl}$. Re-activation was carried out $2400 \mathrm{~s}$ after the pit formation.
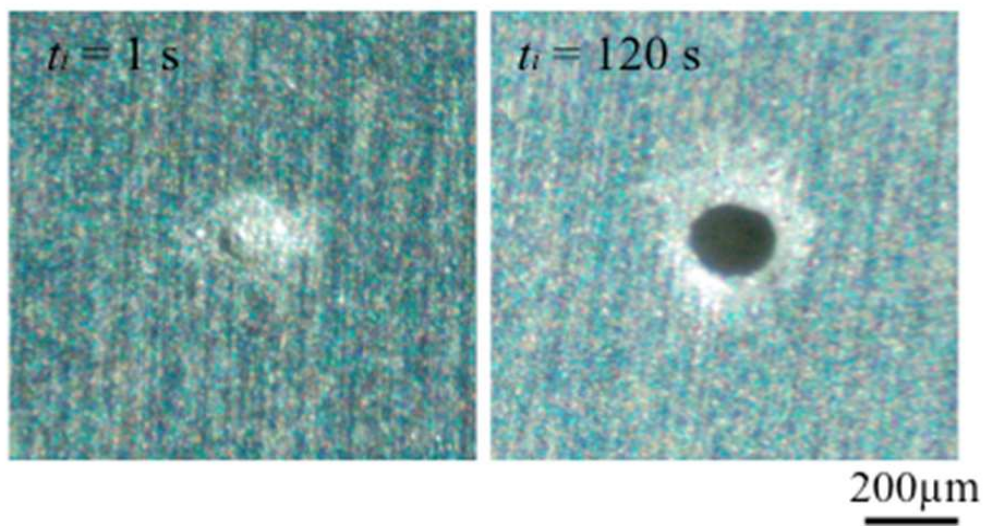

Fig. 19. Optical images after the re-activation tests in Fig. 18.

in the figures. It is clearly shown that $r_{p}$ at $0.01 \mathrm{~s}$ decreases with the aspect ratio of the pit (Fig. 21) while at $10 \mathrm{~s}$ it increases with aspect ratio (Fig. 22). At both $t_{c}$, the $r_{p}$ of the 2024 aluminum alloy is higher than that of the 1050 aluminum alloy. These results suggest that the repassivation rate of the 2024 aluminum alloy is faster than that of the 1050 aluminum alloy in low $\mathrm{NaCl}$ containing solutions.

Figure 23 shows a schematic representation of the situation after activation at the bottom of a pit, (a) transfer of oxygen and (b) selection of anodic and cathodic sites and transfer of hydrogen. With 2024 aluminum alloy, a number of copper rich intermetallics are present in the substrate. In the pit as formed by laser irradiation, these intremetallics may be exposed to the solution and act as cathodic reaction sites during immersion corrosion tests. 
In the pit here, the main cathodic reaction is oxygen reduction because the solution $\mathrm{pH}$ is close to neutral and no nitrogen or argon gas was bubbled into the solution. The exposed area of the intermetallics in the pit wall may also increase with aspect ratio and cause the increasee in cathodic partial current, $i_{c}$, in Fig. 17. Here, as the anodic partial current, the dissolution of aluminum is increased by the re-activation, and there are no large rest potential changes. This also means an acceleration in the rate of passivation in low $\mathrm{NaCl}$ containing solutions. This may be concluded to be the reason why the $r_{p}$ of the 2024 aluminum alloy is lager than that of the 1050 aluminum alloy in Figs 21 and 22.

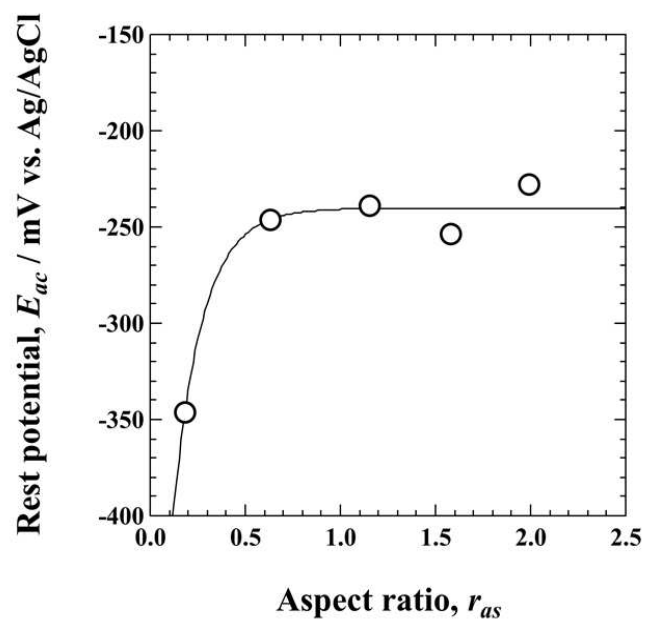

Fig. 20. Lowest rest potentials after the re-activation as a function of aspect ratio in $0.5 \mathrm{kmol}$ $\mathrm{m}^{-3} \mathrm{H}_{3} \mathrm{BO}_{3}-0.05 \mathrm{kmol} \mathrm{m}^{-3} \mathrm{Na}_{2} \mathrm{~B}_{4} \mathrm{O}_{7}$ with $0.001 \mathrm{kmol} \mathrm{m}^{-3} \mathrm{NaCl}$.

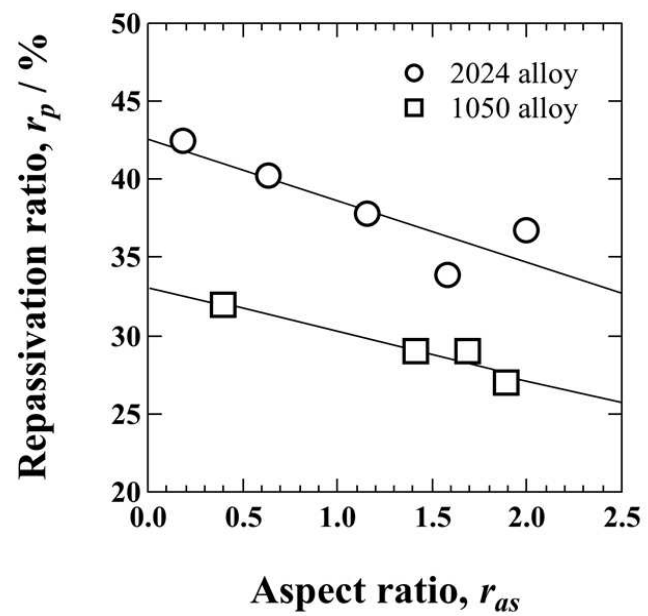

Fig. 21. Changes in repassivation ratios at $0.01 \mathrm{~s}$ with different aspect ratios of pits in 0.5 $\mathrm{kmol} \mathrm{m}^{-3} \mathrm{H}_{3} \mathrm{BO}_{3}-0.05 \mathrm{kmol} \mathrm{m}^{-3} \mathrm{Na}_{2} \mathrm{~B}_{4} \mathrm{O}_{7}$ with $0.001 \mathrm{kmol} \mathrm{m}^{-3} \mathrm{NaCl}$. 


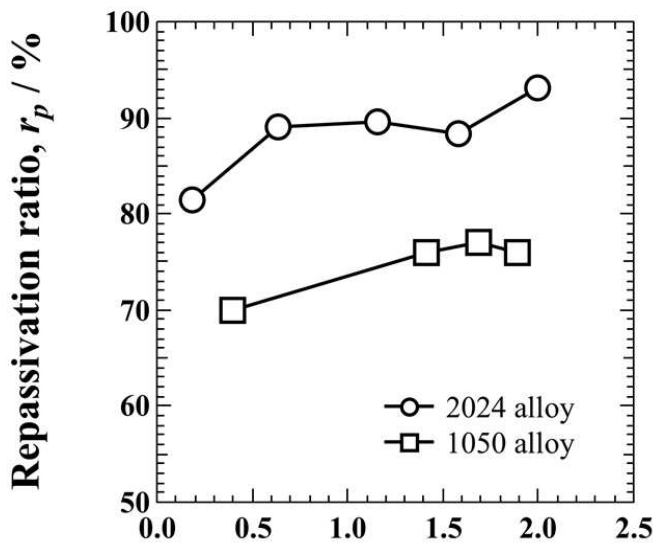

Aspect ratio, $r_{a s}$

Fig. 22. Changes in repassivation ratios at $10 \mathrm{~s}$ with different aspect ratios of pits in $0.5 \mathrm{kmol}$ $\mathrm{m}^{-3} \mathrm{H}_{3} \mathrm{BO}_{3}-0.05 \mathrm{kmol} \mathrm{m}^{-3} \mathrm{Na}_{2} \mathrm{~B}_{4} \mathrm{O}_{7}$ with $0.001 \mathrm{kmol} \mathrm{m}^{-3} \mathrm{NaCl}$.

After some time, dissolved oxygen in the solution inside the pit may be consumed and oxygen diffuse from the bulk solution to the pit. In the high aspect ratio pit, the distribution of oxygen concentrations becomes dominant dividing the cathodic reaction (near the pit mouth) and anodic reaction areas (near the pit bottom) in the pit (Fig. 23 (b)). This means that the dissolution rate of aluminum at the bottom also increases. The dissolved $\mathrm{Al}^{3+}$ reacts with water to form $\mathrm{H}^{+}$and lowers the $\mathrm{pH}$ locally. The higher aspect ratio makes it difficult to dilute the $\mathrm{H}^{+}$ ions at the pit bottom, and this is a possible reason why the $r_{p}$ at $0.01 \mathrm{~s}$ decreases with increasing aspect ratio. At $t_{c}=10 \mathrm{~s}$, the $\mathrm{pH}$ at the bottom of the pit may increase because of buffer reactions of the Borate and diffusion of $\mathrm{H}^{+}$ion into the bulk solution. The cathodic reaction rate of the high aspect ratio pit is still faster than that of the low aspect ratio pit. This fast cathodic reaction may make it easier to achieve repassivation at the bottom of the pit.

\section{Summary}

In this chapter, the application of a new in-situ artificial micro-pit formation method with an area selective electrochemical measurement technique was explained. The technique showed here uses focused pulsed Nd-YAG laser irradiation and anodizing. This technique was applied to investigate the effect of the geometry (aspect ratio) of artificially formed pits on the localized corrosion behavior of the formed artificial pits in aluminum alloys. The following conclusions may be drawn.

1. By controlling the laser irradiation time it becomes possible to form artificial micro-pits with different aspect ratios. An aspect ratio of about 2 is obtained by $120 \mathrm{~s}$ of laser irradiation.

2. The pit formation rate of the $2024 \mathrm{Al}$ alloy is about four times slower than that 1050 Al alloy.

3. The rest potential of the pits at $2400 \mathrm{~s}$ after completion of pit formation, $\mathrm{E}_{2400}$, becomes lower with increasing aspect ratio.

4. The repassivation ratio at $0.01 \mathrm{~s}$ after activation becomes lower with increasing aspect ratio. 


\section{References}

Ito, G. Ishida, S. Kato, M. Nakayama, T. and Mishima, R. (1968). Effect of minor impurities in water on the corrosion of aluminum, Keikinzoku, Vol. 18, No. 10, pp. 530-536, ISSN 0451-5994.

Horibe, K. (1969). Pit formation on aluminum immersed in artificial waters II, Keikinzoku, Vol. 19, No. 3, pp. 105-110, ISSN 0451-5994.

Goto, K. Ito, G. and Shimizu, Y. (1970). Effect of some oxidizing agents on pitting corrosion of aluminum in neutral water, Keikinzoku, Vol. 20, No. 2, pp. 88-94, ISSN 0451-5994.

Blanc, C. Lavelle, Mankowski, B. G. (1997). The role of precipitates enriched with copper on the susceptibility to pitting corrosion of the 2024 aluminium alloy, Corrosion Science, Vol. 39, No. 3, pp. 495-510, ISSN 0010-938X.

Kang, J. Fu, R. Luan, G. Dong, C. and He, H. (2010). In-situ investigation on the pitting corrosion behavior of friction stir welded joint of AA2024-T3 aluminium alloy, Corrosion Science, Vol. 52, No. 2, pp. 620-626, ISSN 0010-938X.

Ioti, Y. Take, S. and Okuyama, Y. (2003). Electrochemical noise in crevice corrosion of aluminum and possibility for its monitoring, Ziryo-to-Kankyo, Vol. 52, No. 9, pp. 471-476, ISSN 0917-0480.

Sakairi, M. Shimoyama, Y. and Takahashi, H. (2005). Electrochemical Noise Study on Galvanic Corrosion of Anodized Aluminum in Chloride Environments, Proceedings of Electrochemical Society, Volume 2004-14, pp. 265-272.

Sakairi, M. Shimoyama, Y. and Takahashi, H. (2006). Electrochemical Noise Study on Galvanic Corrosion of Aluminum Alloy in Chloride Environments- Effect of Oxide Film Structure, ECS Transactions, Vol. 1, No. 4, pp. 195-206, ISSN 1938-6737.

Sakairi, M. and Shimoyama, Y. (2007). Electrochemical Random Signal Analysis During Galvanic Corrosion of Anodized Aluminum Alloy, Journal of Japan Society for Experimental Mechanics, Special Issue, pp. 114-119 ISSN 1346-4930.

Tohma, K. and Yamada, K. (1980). Change of corrosion potentials of aluminum and aluminum alloys with pit growth, Keikinzoku, Vol. 30, No. 2, pp. 85-91, ISSN 04515994.

Sakairi, M. Kageyama, A. Kojima, Y. Oya, Y and Kikuchi, T. (2009). Effect of aspect ratio of artificial pits formed on Al by PRM on localized corrosion in chloride environments, ECS Transactions, Vol. 16, No. 43, pp. 19-21, ISSN 1938-6737.

Yanada, K. Sakairi, M. Kikuchi, T. Oya, Y. and Kojima, Y. (2010). Formation of artificial micro-pits on $\mathrm{Al}$ alloy with PRM and the localized corrosion behavior of the formed pits, Surface and Interface Analysis, Vol. 42, pp. 189-193, ISSN 1096-9918.

Sakairi, M. Uchida, Y. Itabashi, K and Takahashi, H. (2007). Re-passivation and initial stage of localized corrosion of metals by using photon rupture technique and electrochemistry, In: Progress in Corrosion Research, Emilio L. Bettini, pp. 133-157, Nova Science Publishers Inc., ISBN 1-60021-734-6, New York.

Weaver J. H. (1991-1992). Optical properties of metals, In: CRC Handbook of Chemistry and Physics, A Ready-Reference Book of Chemical and Physical Data 72nd., Lide, D.R., CRC Press Inc., p. 12-101, ISBN 0-8493-0472-5, Boston.

Ready, J. F. (1971). Emission, In: Effect of High Power Laser Radiation, Academic Press, New York. 
Scruby, C. B. Drain, L. E. (1990). Ultrasonic generation by laser, In: Laser Ultrasonics Techniques and Applications-, Adam Hilger pp. 223-274, ISBN 0-7503-0050-7, New York.

Hoshino, S. Suzuki, K. and Nakane, K. (1997). Characteristics of microfilters made of anodic oxide films of aluminum, Transactions of the Institute of Metal Finishing, Vol. 75, No. 4, pp. 134 - 137, ISSN 0020-2967.

Sakairi, M. Wakabayashi, J. Takahashi, H. Abe, Y. and Katayama, N. (1998). Journal of The Surface Finishing Society of Japan, Vol. 49, No. 11, pp 1220-1232, ISSN 0915-1869. 


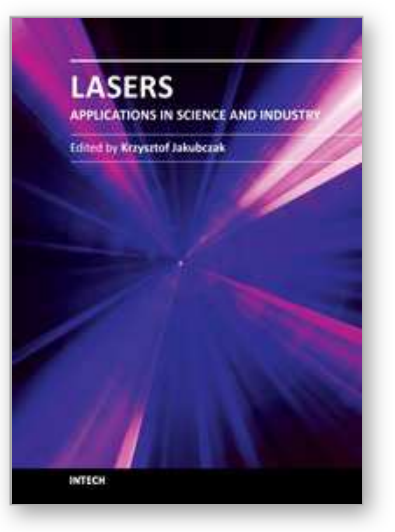

\author{
Lasers - Applications in Science and Industry \\ Edited by Dr Krzysztof Jakubczak
}

ISBN 978-953-307-755-0

Hard cover, 276 pages

Publisher InTech

Published online 09, December, 2011

Published in print edition December, 2011

The book starts with basic overview of physical phenomena on laser-matter interaction. Then it is followed by presentation of a number of laser applications in the nano-particles and thin films production, materials examination for industry, biological applications (in-vitro fertilization,tissue ablation) and long-range detection issues by LIDARs.

\title{
How to reference
}

In order to correctly reference this scholarly work, feel free to copy and paste the following:

M. Sakairi, K. Yanada, T. Kikuchi, Y. Oya and Y. Kojima (2011). Application of Pulsed Laser Fabrication in Localized Corrosion Research, Lasers - Applications in Science and Industry, Dr Krzysztof Jakubczak (Ed.), ISBN: 978-953-307-755-0, InTech, Available from: http://www.intechopen.com/books/lasers-applications-inscience-and-industry/application-of-pulsed-laser-fabrication-in-localized-corrosion-research

\section{INTECH}

open science | open minds

\author{
InTech Europe \\ University Campus STeP Ri \\ Slavka Krautzeka 83/A \\ 51000 Rijeka, Croatia \\ Phone: +385 (51) 770447 \\ Fax: +385 (51) 686166 \\ www.intechopen.com
}

\author{
InTech China \\ Unit 405, Office Block, Hotel Equatorial Shanghai \\ No.65, Yan An Road (West), Shanghai, 200040, China \\ 中国上海市延安西路65号上海国际贵都大饭店办公楼405单元 \\ Phone: +86-21-62489820 \\ Fax: +86-21-62489821
}


(C) 2011 The Author(s). Licensee IntechOpen. This is an open access article distributed under the terms of the Creative Commons Attribution 3.0 License, which permits unrestricted use, distribution, and reproduction in any medium, provided the original work is properly cited. 